\title{
Giant Temporal Lobe Cholesteatoma
}

\author{
Sabri Ibrahim* \\ Department of Neurosurgery, Faculty of Medicine, Universitas Sumatera Utara, Indonesia
}

\begin{abstract}
Edited by: Igor Spirosk Citation: Ibrahim S. Giant Temporal Lobe Cholesteatoma Open Access Maced J Med Sci. 2020 Apr 15; 8(C):49-5 https://doi.org/10.3889/oamjms.2020.417 Keywords: Cholesteatoma; Pearl tumor; Epidermoid cys "Correspondence: Sabri Ibrahim, Department of Utara, Indonesia. E-mail: sabriibrahimmnc@usu.ac.id Received: 08-Dec-2019 Revised: 07-Feb-2020 Accepted: 07-Mar-2020 Copyright: ๑ 2020 Sabri lbrahim Funding: This research did not receive any financial Competing Interests: The authors have declared that competing iared that no competing interests exis Open Access: This is an open-access article distribute oncommercial 4 . International License (CC BY-NC 4.0)

\section{Abstract}

INTRODUCTION: Intracranial cholesteatoma is uncommon about $0.2-1.8 \%$ of all tumor lesions, composed of desquamated debris lined by keratinized squamous epithelium, divided into congenital and acquired. Congenital cholesteatoma occurred early, while acquired cholesteatoma associated with otitis media.

CASE REPORT: Case-1 18-year-old male with 2 years recurrent seizures, 2 times per week, lasted 1-3 min headache, left-sided hemiparesis, and right-sided hearing impairment at 10 years from chronic suppurative otitis media at 5 years old. Brain magnetic resonance imaging (MRI) examination revealed a mass on the right temporal base measured $5.8 \times 6.2 \mathrm{~mm}$. Surgery was done, histopathology revealed cholesteatoma. Two weeks post-operative, normal motoric with no seizures. Case-2 45-year-old male, complaining motor aphasia for 2 years, hemiparesis for 1 year, seizures in a month, headache, and impairment of left-sided hearing. MRI examination revealed a large mass at the left temporal. Surgery was done, histopathology revealed cholesteatoma. Five days post-operative, the patient talked in slow speech and normal function achieved a month after. Cholesteatoma is a rare benign lesion, described as misplaced skin, divided into intracranial, the external auditory canal and otitis media, found commonly at the frontal or temporal bone. Infection of Streptococcus spp., MRSA, and Pseudomonas aeruginosa is common. In our case, no positive culture was found. Commonly has good surgical prognosis, neurological deficit, otorrhea, tumor recurrence, and infection was not found on our yearly follow-up.
\end{abstract}

CONCLUSION: Cholesteatoma, as a non-invasive lesion compared to other intradural lesions, presents with atypica symptoms, signs, and images.

\section{Introduction}

Intracranial cholesteatoma is an uncommon condition that is usually regarded as one of the important diseases involved in neurosurgery. Although considered rare, the incidence of intracranial cholesteatoma is on the rise, and now, it accounts for $0.2-1.8 \%$ of all tumor lesions [1]. Cholesteatomas are epidermal inclusion cysts composed of desquamated debris lined by a keratinized squamous epithelium. It may be congenital or acquired. Congenital cholesteatomas are believed to result from abnormal development of the first branchial groove depositing ectopic ectodermal tissue within the temporal bone or intracranially mainly at the cerebellopontine angle. Acquired cholesteatomas originate at the middle ear or mastoid and are associated with otitis media and eustachian tube dysfunction. The pathogenesis is proposed by four main theories: Invagination, basal cell hyperplasia, epithelial invasion, and squamous metaplasia. The invagination theory explains the formation of attic cholesteatomas. Retraction of pars flaccida due to the negative pressure of the middle ear results in altered epithelial migration and accumulation of desquamated keratin debris [2].

\section{Case-1}

A 18-year-old male with recurrent seizure in the past 2 years, frequency 2 times per week, duration 1-3 min, chronic headache, and slight left side weakness, decrease hearing function on the right side for 10 years ago. A history of chronic suppurative media otitis on 5-7 years of age. On brain magnetic resonance imaging (MRI) examination, we found mass on the right temporal base with the size of $5.8 \times 6.2 \mathrm{~mm}$, midline shift to the left of $8 \mathrm{~mm}$, we can see that brain stem was pushed, T1 showed slight enhancement on tumor capsule, lower pole of the tumor is the temporal base (Figure 1). The patient undergone operation with general anesthesia. Supine position with the craniotomyzygomatectomy subtemporal approach. After dura mater was opened, the tumor was seen in pearly white mass, avascular, fragile, with the central necrotic component. Tumor easily separated from healthy brain tissue and achieved gross total removal. Histopathology report is cholesteatoma. Two weeks after the operation, motoric function back to normal and no more seizure was found. After 3 months post-operative, we did another brain MRI contrast and no tumor residue was found with brain compliance almost normal. 


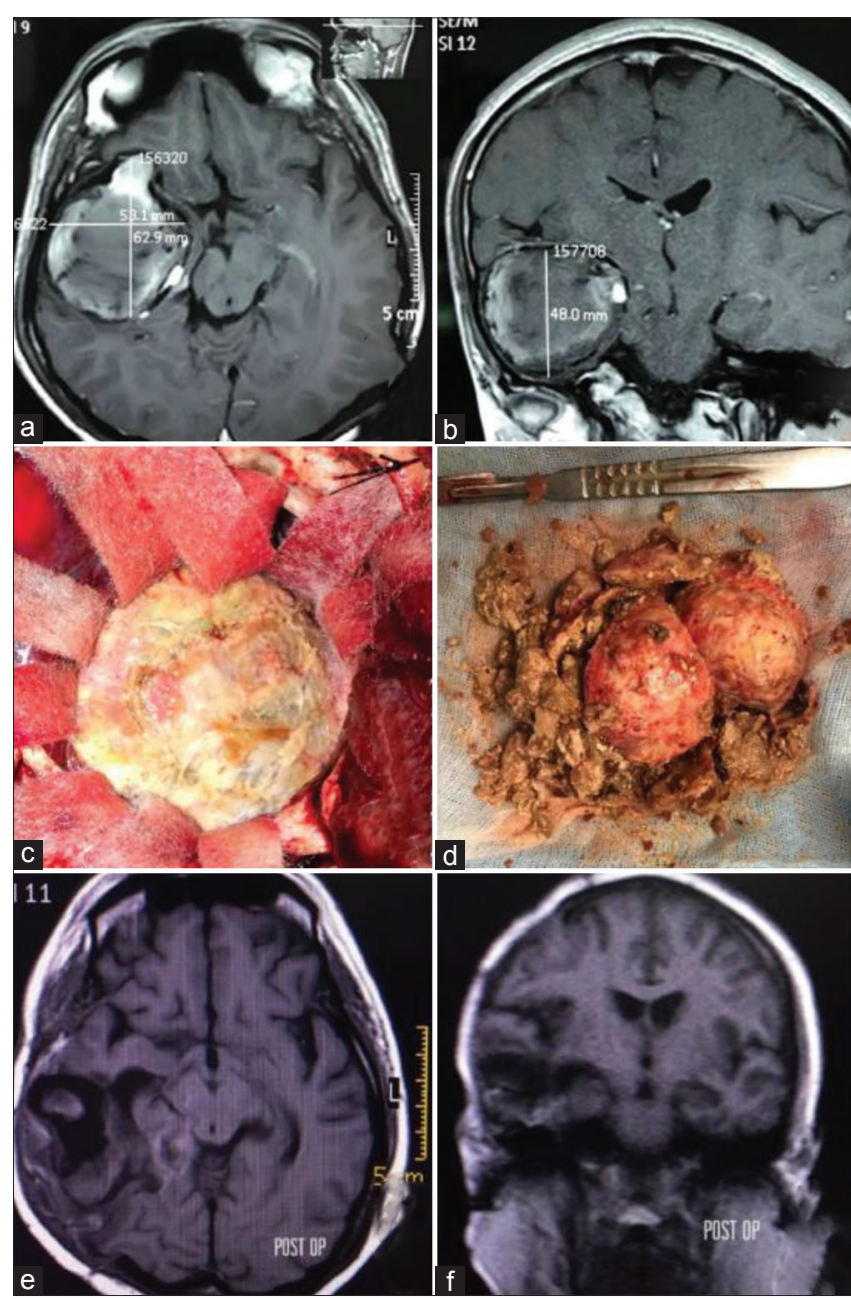

Figure 1: ( $a$ and b) Magnetic resonance imaging (MRI) brain contrast axial view and coronal view show extra-axial mass on the right temporal base, the capsule slightly enhanced with contrast, minimal compression on the brain stem. (c and d) Intraoperative picture of tumor, tumor was seen in pearly white mass, avascular, fragile, with central necrotic component, (e and f) post-operative MRI brain contrast shows that no tumor residue was found with brain compliance almost normal

\section{Case-2}

A 45-year-old male, with the main complaint of motor aphasia for 2 years, slights hemiparesis for 1 year, history of seizures since the past 1 month, headache and impairment of left-sided hearing. MRI brain contrast examination was performed, there was a large mass at the left temporal, the lower pole of the tumor was a temporal base, with a $15 \mathrm{~mm}$ midline shift, and mass no enhance with contrast (Figure 2). The patient was operated with general anesthesia, supine position, right subtemporal craniotomyzygomatectomy, after the dura mater was opened, visible temporal lobes, operating corridor was made through subtemporal with temporal lobe retraction, visible pearly white mass tumors, avascular, fragile, tumors very easily separated with healthy brain tissue, gross total removal was achieved, histopathology report is cholesteatoma (Figure 3). Five days after surgery, the patient can start talking but is still slow; after 1 month, surgery ability to talk and normal motor function was achieved.

\section{Discussion}

Cholesteatoma, first described by JosephGuichard Duverney, is a well-demarcated, nonneoplastic, temporal bone lesion often described as skin in the wrong place. It is considered a misnomer and keratoma and epidermoid cyst are other possibly more accurate names suggested to describe the same [3], [4]. Epidermoid cyst, which is also known as cholesteatoma or pearl tumor, is a rare benign lesion that accounts for less than $1 \%$ of all primary intracranial neoplasms [5]. It can be divided into intracranial cholesteatoma, external auditory canal cholesteatoma, and cholesteatoma otitis media depending on its location of the distribution. Etiology of the epidermoid cyst (cholesteatoma) is still controversial; however, a result of the neural tube closure with the ectoderm composition during the embryonic period about 3-5 weeks of gestation may be the most acceptable reason [6]. Michaels suggested that it may originate from residual cells divided from the ectoderm
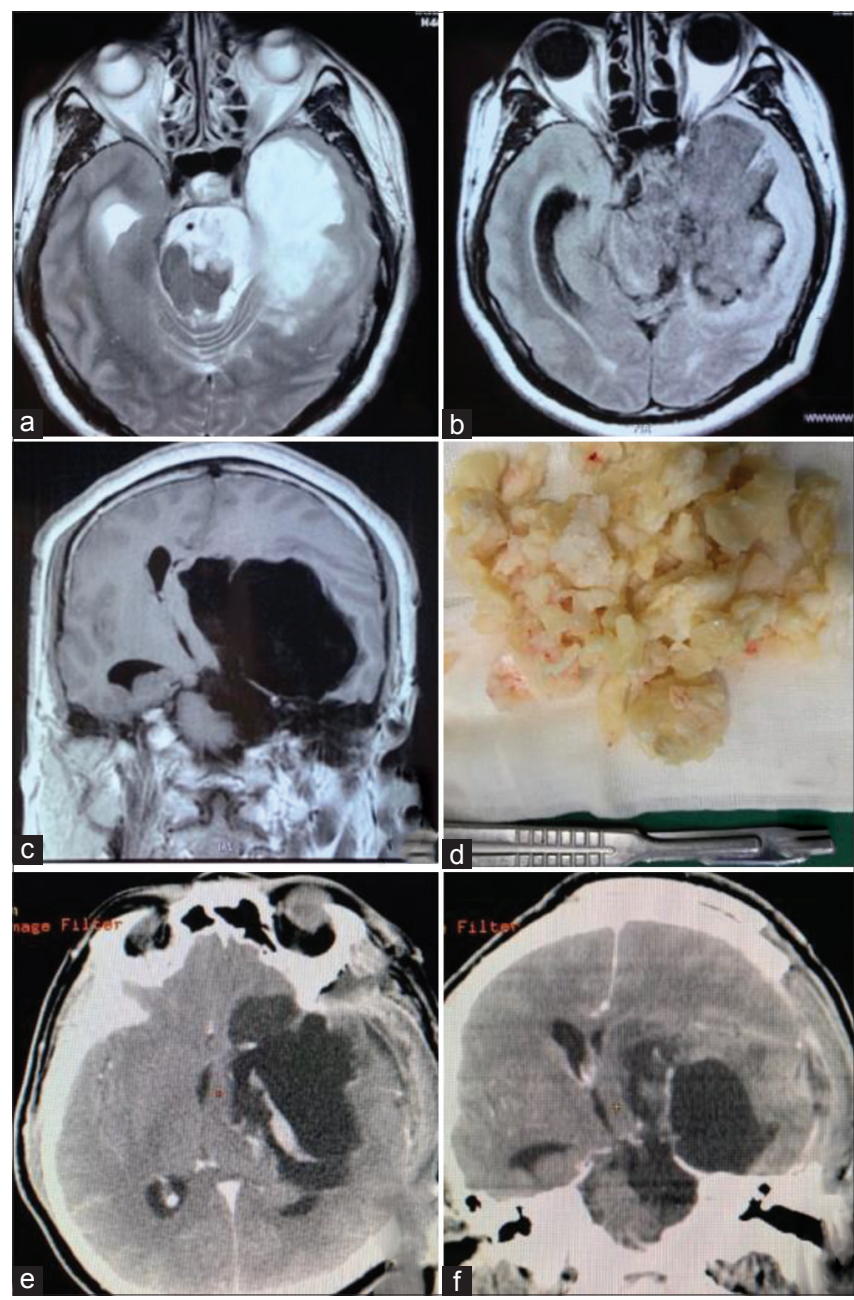

Figure 2: (a-c) Magnetic resonance imaging brain contrast preoperative shows giant extra-axial mass on the left temporal base, no enhance with contrast, (d) picture of tumor intraoperatively, tumor was seen in pearly white mass, avascular and fragile, and (e and f) post-operative computed tomography scan brain contrast shows that no tumor residue was found 


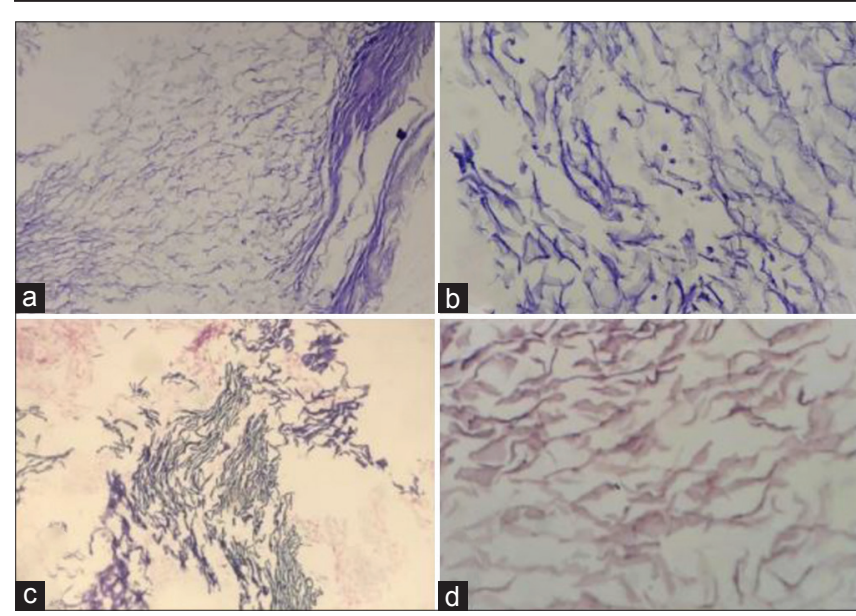

Figure 3: (a-d) Picture shows histopathology result of tumor which shown keratinized mass with amorf basophilic and calcification. It was also seen as mononuclear inflammation cell and interstitial bleeding. No dysplastic cell or malignancy is suspected

of the first branchial groove in embryonic and early in fetal life when the neural tube closes. An epidermoid cyst (cholesteatoma) was especially common in the sites of the frontal and temporal bone [7].

Although some literature said anaerobic bacteria are encountered in $67 \%$ of acquired cholesteatoma includes Bacteroides spp., the facultative anaerobes such as Streptococcus spp. and MRSA. Pseudomonas aeruginosa is the most common aerobe. The coinfection of anaerobes and aerobes is observed in $50 \%$ of acquired cholesteatomas [8], [9]. In two of our case, there are no bacterial growth in the microbiological examination and no sign of infection from pre-operative blood work. In both of our cases, we found the destruction of the temporal bone with intact dura mater and no sign of infection. The operation was done easily since tumor is avascular, with no adhesion to brain tissue and easy to removed. The prognosis of intracranial cholesteatoma surgery remains good. In the current largest series of 43 patients by Mo et al., there have been no perioperative deaths and no long-term recurrence in $95.4 \%$ of patients with a median follow-up of 10 years [10]. In our cases, we did 1-year follow-up and no neurological deficit, otorrhea, tumor recurrence, and infection.

\section{Conclusion}

Compared with other intradural lesions, there are no typical representations of symptoms, signs, and images. Cholesteatoma with big size can come with the minimal symptoms because tumor grow slowly and no invasion of brain tissue.

\section{References}

1. Darrouzet $V$, Francovidal $V$, Hilton $M$, Nguyen $D Q$, Lacherfougere S, Guerin J, et al. Surgery of cerebellopontine angle epidermoid cysts: Role of the widened retrolabyrinthine approach combined with endoscopy. Otolaryngol Head Neck Surg. 2004;131(1):120-5. https://doi.org/10.1016/j. otohns.2004.02.023

PMid: 15243568

2. Waidyasekara $P$, Dowthwaite $S A$, Stephenson E, Bhuta $S$, McMonagle B. Massive temporal lobe cholesteatoma, Hindawi publishing corporation. Case Rep Otolaryngol. 2015;2015:4. https://doi.org/10.1155/2015/121028

3. Barath K, Huber AM, Stampfli P, Varga Z, Kollias S Neuroradiology of cholesteatomas. Am J Neuroradiol. 2011;32(2):221-9. https://doi.org/10.3174/ajnr.a2052 PMid:20360335

4. Robinson JM. Cholesteatoma: Skin in the wrong place. J R Soc Med. 1997;90(2):93-6.

PMid:9068441

5. Lee DH. Intradiploic epidermoid cyst of the temporal bone: Is it the same as or different from cholesteatoma? J Craniofac Surg. 2011;22(5):1973-5. https://doi.org/10.1097/ scs.0b013e31822eaa52

PMid:21959487

6. Desouza CE, Menezes CO, Desouza RA, Ogale SB, Morris M, Desai AP. Profile of congenital cholesteatomas of the petrous apex. J Postgrad Med. 1989;35(2):93-7.

PMid:2695622

7. Michaels L. Origin of congenital cholesteatoma from a normally occurring epidermoid rest in the developing middle ear. Int J Pediatr Otorhinolaryngol. 1988;15(1):51-65. https://doi. org/10.1016/0165-5876(88)90050-x

\section{PMid:3286554}

8. Harker LA, Koontz FP. Bacteriology of cholesteatoma: Clinical signi cance. Trans Sect Otolaryngol Am Acad Ophthalmol Otolaryngol. 1977;84(4 Pt 1):ORL 683-6.

9. Quaranta N, Chang P, Moffat DA. Unusual MRI appearance of an intracranial cholesteatoma extension: The "billiard pocket sign". Ear Nose Throat J. 2002;81(9):645-7. https://doi. org/10.1177/014556130208100912 PMid: 12353441

10. Moffat D, Jones S, Smith W. Petrous temporal bone cholesteatoma: A new classi cation and long-term surgical outcomes. Skull Base. 18(2):107-11 https://doi. org/10.1055/s-2007-991112

PMid:18769653 